\title{
Understanding Occupant Behaviour in Islamic Homes to Close the Gap in Building Performance Simulation: A Case Study of Houses in Riyadh
}

\author{
Mohammed Aljammaz, Tsung-Hsien Wang, Chengzhi Peng \\ School of Architecture, The University of Sheffield, Sheffield, United Kingdom
}

\begin{abstract}
This study explores the influence of Saudi Arabian culture on the use of energy in domestic buildings. Building occupation/load schedules are used to simulate and predict energy-using activities. However, the effective use of this method depends on accurate load schedules. Failure to achieve this can result in a mismatch between predicted and actual energy use of up to $40 \%$. Cultural and behavioural factors have a significant impact on the assumptions incorporated within the load schedules and it is, therefore, important to look at these features in detail. Using a time use data (TUD) survey, it is possible to improve the accuracy of this information, which can reduce the mismatch to $15 \%$.
\end{abstract}

\section{Introduction}

Five main inputs are required to predict/simulate energy consumption for any building. The inputs are climate, geometry, material, load schedules, and systems. The accuracy of the predicted energy consumption depends on whether the five inputs are representative of actual energy use. At the inception of prediction methods in the 1960s, this gap could be 2.5 times the real energy use (de Wilde, 2014a). At that time, a gap of this magnitude was acceptable (Clarke, 2001). However, by the mid-1990s, with the increase in energy prices, it became essential to address this performance gap (Norford et al, 1994). In addition, governments around the world set codes for companies and factories to control and reduce the amount of energy consumed. To facilitate this, designers need more accurate data and predictions to meet the requirements. As part of this demand, software developers have designed more sophisticated simulation methods that have reduced the level of mismatch to about $30 \%$ (Sunikka-Blank and Galvin, 2012). The software outcome gap is identified in other indices such as thermal comfort, indoor air quality, acoustic performance, and daylight levels; the more data provided as an input to the software, the more accurate the outcome will be (Oberkampf, 2010). One method used to close the gap is to adapt to the changing conditions, including occupant and climate change proofing (de Wilde, 2014a).

One of the main factors that needs to be considered in order to close the gap are the load schedules for occupant behaviours (Sunikka-Blank and Galvin, 2012; Martinaitis et al, 2015) Load schedules are the parameter representing the end-use energy activities of occupants and pose a significant challenge for modelling due to the unpredictable and dynamic nature of occupant behaviours (Paatero, 2006). The impact of people's behaviours also concerns governments and institutions. Several initiatives have been taken to understand such behaviours pertaining to energy usage. One of the main factors that led to previous inaccuracies in simulated estimations was inaccurate assessment and knowledge of people's behaviour and activity in any given building (Yoshino, Hong and Nord, 2017). People's behaviour gives a better understanding of energy use in buildings and defines the necessary calculation inputs for energy simulation. It is difficult to obtain exact measurements of energy usage in the real world, but users can reduce the mismatch to an acceptable level. Higher accuracy is achievable when exact input data are available, especially information on building occupancy patterns and activities (Korjenic and Bednar, 2012). Therefore, for residential buildings, passive or user-friendly active measures are significant. At present, the standardised assessments assume a very high energy usage that does not reflect usage based on realistic assessments of occupancy (Yu et al, 2011).

Several researchers have discovered that the default load schedules do not represent real occupant behaviour in their countries. In response, they conducted TUD surveys to obtain more accurate behaviour data and to generate new occupancy schedules (Lamedica, 1994). For example, Widén et al. (2009a) developed a computational framework that could generate a comprehensive thermal model considering realistic energy behavioural patterns. The aim was to prove that the TUD has high potential for load modelling in terms of occupant behaviour, which can introduce realistic behavioural patterns into various simulations. A TUD survey was conducted by Statistics Sweden (SCB) in a pilot study in 1996. Wilk (2012) presented a bottom-up stochastic method to simulate domestic occupancy behaviours in France and generated occupancy-driven load schedules from French time-use survey data during the period 1998-1999. Since then, TUD surveys have been adopted widely by researchers from the UK (data collector form attained from NatCen Social Research), France and Sweden to incorporate occupants' behaviours into energy performance simulations to improve energy consumption predictions. 
Residential occupancy in Saudi Arabia is influenced by the impacts of Islamic culture on lifestyle. For example, according to Islam, a Muslim woman should cover her hair when she is in the presence of non-family males. This aspect of Islamic culture has had a significant influence on building design and energy use in houses (Al-Said, 2003). In Riyadh, for instance, two reception rooms are often used, one for male visitors and the other for female, because they must stay separate during visits (Alhemaidi, 1996). Several studies have examined how Islamic culture influences building construction. Al-Hussayen (1980) compared two types of houses: (1) traditional houses were built with high regard for privacy and the hot climate. Designs incorporated a central courtyard, with most of the windows of the surrounding buildings facing the courtyard, except for guest rooms, which faced outwards. This traditional house also used thick exterior walls to reduce the flow of heat. (2) The climate is less of a consideration in designs for modern houses. This is less efficient in terms of energy consumption, but the design still adheres to cultural requirements for privacy. In a contemporary residential building, there are two zones one for male guests and the other for females and family - which are separated visually to meet the obligations of Saudi Arabian culture.

Figure 1 illustrates the levels of privacy considered in designs for traditional and modern Saudi Arabian houses, redrawn from Akbar (1981). The lowest level of privacy is outside and the levels increase to embrace spaces for male guests, then female guests, and then for family and relatives. The highest level is individual privacy. Each of these levels has an expectation regarding the amount of time for which it will be used and this is further reflected in the design (Othman, Aird, and Buys, 2015).

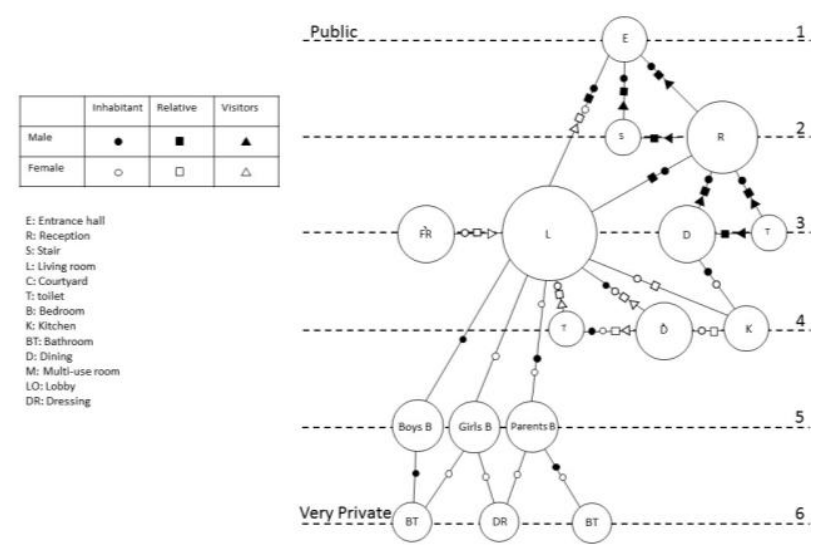

Figure 1: Level of privacy in Saudi houses (Akbar, 1981).

In a study conducted at the University of Southern California, Aljammaz and Schiler (2016) compared the energy use of residential buildings in Riyadh $\left(24.7136^{\circ} \mathrm{N}\right.$, $\left.46.6753^{\circ} \mathrm{E}\right)$ and Los Angeles $\left(34.0522^{\circ} \mathrm{N}, 118.2437^{\circ} \mathrm{W}\right)$ using two scenarios. The first scenario was to build models for villas in Riyadh and Los Angeles and run the energy simulation using Green Building Studio. The second scenario was to run the model using additional data to reflect peoples' behaviour and use of space. These two cities provide useful comparisons because they have similar climates and use similar factors when running energy programme simulations. Behaviour data were collected from 80 residents of Riyadh. Seventeen questions were asked about how they used their space. The same questions were then asked of 80 residents in Los Angeles to allow the effects of cultural differences to be identified. One outcome of the survey was that, in Riyadh, people generally did not use their windows as much as in Los Angeles. Californian residents tended to use windows to enjoy the view; this was less common in Saudi Arabia due to cultural standards of privacy. Evidence from previous studies shows that occupant behaviour is influenced by culture, which has a significant impact on energy use in domestic buildings. In this paper, we focus on Saudi Arabian culture. The objective is to investigate and find the most effective factors and parameters that influence energy use in buildings. In this study, we tested four different scenarios on a case study house in Riyadh, Saudi Arabia. The simulation results demonstrated the extent to which gaps between energy prediction and the real amount of energy used can be closed if cultural behaviour influencing energy end-use is taken into consideration.

\section{Case Study}

The case study was used to test the methodology and to aid in the design of a questionnaire that would yield the most accurate results in energy-use simulation models for Riyadh, Saudi Arabia. The following sections show how different stages of modelling influence energy-use predictions and how the incorporation of data from surveys and interviews can influence the accuracy of these energy-use predictions.

\section{Building Description}

The case study was based on a standard house in Riyadh, built in 2005. The house (villa) has a basement, ground floor, first floor, and second floor. It is inhabited by six occupants. The villa's total floor area is 500 square metres; it has double-glazed windows and $30 \mathrm{~cm}$-thick concrete exterior walls with $8 \mathrm{~cm}$ of insulation. Figures 2 and 3 present the layout of the case study house. The first two plans (Figure 2) show the basement, where friends gather, and the ground floor, where guests stay. The grey area highlights the male guest zone, which male guests are allowed to use. The third plan shows the first floor (Figure 3 ), which contains all the bedrooms and is where the family gathers. The fourth plan shows the second floor, consisting of storage and service rooms.

The house was modelled using OpenStudio. The detailed inputs were provided by the landlord and the architectural design company. The case study went through four different experimental stages: defining the problem (two stages), testing the model, and conducting interviews. 


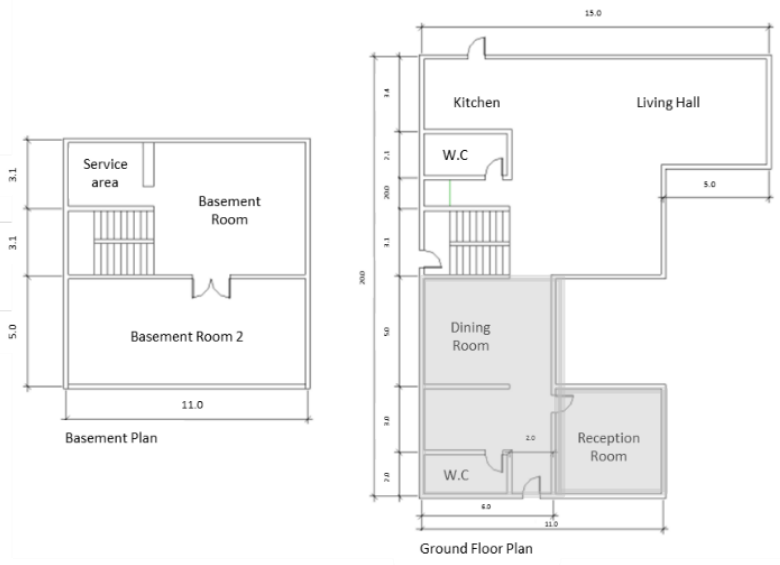

Figure 2: Layout of the case study house in Riyadh (basement and ground floor).
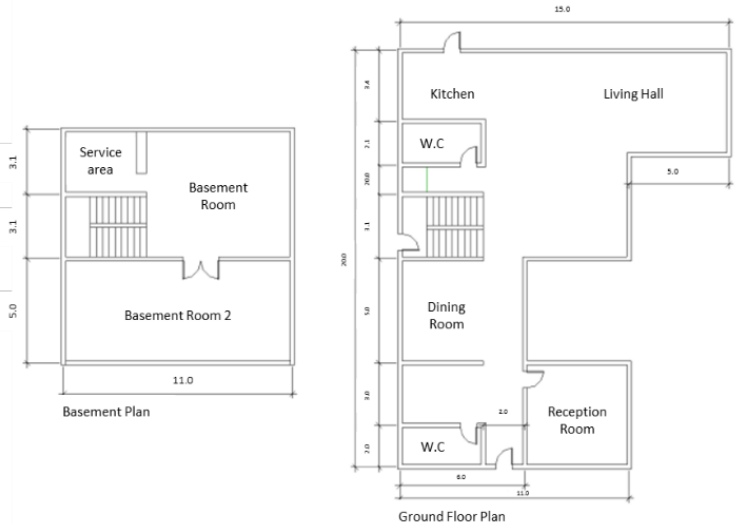

Figure 3: Layout of the case study house in Riyadh (first floor and second floor).

Table 1: ASHRAE standards of the building envelope for a hot dry climate.

\section{Problem definition}

The first experimental stage was to run simulations to identify the gap between energy predictions and real energy use without considering occupant behaviour. Then, the electricity consumption estimate was compared to actual electricity bills for 2016 and 2017. The gap reflected an approximate $40 \%$ increase in the predicted energy use over the actual energy used.

The second experimental stage was to simulate the materials used in the construction of the building and to identify any influence that this might have had on the gap between the predicted energy consumption and the actual energy use. The results were very similar to simulations that used default material data. OpenStudio energy software provided default material data based on the location of the building, its climate, and material data provided by the American Society of Heating, Refrigerating and Air-Conditioning Engineers (ASHRAE) and EnergyPlus. The ASHRAE climate zone for Riyadh is $1 \mathrm{~B}$, where 1 means very hot and $\mathrm{B}$ means dry.

The energy consumption estimate of the second experiment was almost equal to the first simulation, with a minor difference of less than $1 \%$. This suggests that the accuracy of the material used in the energy consumption software is high. The result demonstrates that the default material provided by ASHRAE was the same as the material provided by the architecture office (Table 1).

\section{Survey}

In order to produce effective questions, we reviewed several cultural studies and other studies that used the TUD method to improve simulations. Based on this, the survey contained 18 questions divided into four sections.

\begin{tabular}{|c|c|c|c|c|c|c|}
\hline \multirow[b]{2}{*}{ Opaque Elements } & \multicolumn{2}{|c|}{ Nonresidential } & \multicolumn{2}{|c|}{ Residential } & \multicolumn{2}{|c|}{ Semiheated } \\
\hline & $\begin{array}{c}\text { Assembly } \\
\text { Max. }\end{array}$ & $\begin{array}{c}\text { Insulation } \\
\text { Min. R-Value }\end{array}$ & $\begin{array}{c}\text { Assembly } \\
\text { Max. }\end{array}$ & $\begin{array}{c}\text { Insulation } \\
\text { Min. R-Value }\end{array}$ & $\begin{array}{c}\text { Assembly } \\
\text { Max. }\end{array}$ & $\begin{array}{l}\text { Insulation } \\
\text { Min.R-Value }\end{array}$ \\
\hline \multicolumn{7}{|l|}{ Roofs } \\
\hline Insulation Entirely above Deck & $\mathrm{U}-0.048$ & $\mathrm{R}-20.0 \mathrm{ci}$ & $U-0.039$ & $\mathrm{R}-25.0 \mathrm{ci}$ & U- 0.173 & $\mathrm{R}-5.0 \mathrm{ci}$ \\
\hline Metal Building & $U-0.044$ & $\mathrm{R}-19.0+\mathrm{R}-11.0 \mathrm{Ls}^{\mathrm{d}}$ & $U-0.035$ & $\mathrm{R}-19.0+\mathrm{R}-11.0 \mathrm{Ls}$ & $U-0.082$ & $R-19.0$ \\
\hline Attic and Other & $U-0.027$ & R-38.0 & $U-0.021$ & $\mathrm{R}-49.0$ & U-0.053 & R-19.0 \\
\hline \multicolumn{7}{|l|}{ Walls, Above Grade } \\
\hline Mass & U-0.151 a & R-5.7 cia & U- 0.123 & $\mathrm{R}-7,6 \mathrm{ci}$ & $\mathrm{U}-0.151^{\mathrm{a}}$ & $\mathrm{R}-5.7 \mathrm{ci}^{\mathrm{a}}$ \\
\hline Metal Building & $U-0.079$ & $\mathrm{R}-13.0+\mathrm{R}-6.5 \mathrm{cl}$ & $U=0.079$ & $R-13.0+R-6.5 \mathrm{ci}$ & U- 0.147 & $R=19.0$ \\
\hline Steel Framed & $\mathrm{U}-0.077$ & $R-13.0+R-5.0 \mathrm{ci}$ & U-0.077 & $\mathrm{R}-13.0+\mathrm{R}-5.0 \mathrm{ci}$ & U-0.124 & $R-13.0$ \\
\hline Wood Framed and Other & $U-0.064$ & $R-13.0+R-3.8 \mathrm{ci}$ & $U-0.064$ & $\mathrm{R}-13.0+\mathrm{R}-3.8 \mathrm{ci}$ & U-0.089 & $R-13.0$ \\
\hline \multicolumn{7}{|l|}{ Wall, Below Grade } \\
\hline Below Grade Wall & $C-1.140$ & NR & $\mathrm{C}-1.140$ & NR & $C-1.140$ & NR \\
\hline \multicolumn{7}{|l|}{ Floors } \\
\hline Mass & U-0.137 & $\mathrm{R}-4.2 \mathrm{ci}$ & U-0.137 & $\mathrm{R}-4.2 \mathrm{ci}$ & $U-0.322$ & NR \\
\hline Steel Joist & $U-0.052$ & $R-19.0$ & U-0.052 & $\mathrm{R}-19.0$ & $U=0.350$ & NR \\
\hline Wood Framed and Other & $U-0.051$ & $R-19.0$ & $U-0.051$ & $\mathrm{R}-19.0$ & U- 0.282 & NR \\
\hline \multicolumn{7}{|l|}{ Slab-On-Grade Floors } \\
\hline Unheated & $F-0.730$ & NR & $F-0.730$ & NR & $F-0.730$ & NR \\
\hline Heated & $F-0.640$ & $\begin{array}{l}\text { R-7.5 for } 12 \text { in. + } \\
\text { R-5 ci below }\end{array}$ & $F-0.640$ & $\begin{array}{l}\text { R-7.5 for } 12 \text { in. + } \\
\text { R-5 ci below }\end{array}$ & $F-1.020$ & R-7.5 for 12 in. \\
\hline
\end{tabular}


- Background information

- Family/owner attributes

- House/room characteristics

- $\quad$ TUD for daily/recreational usages

The survey was then tested and modified using data collected from the case study house. The first section of the survey focused on personal information, such as the ages of the occupants. The second section asked questions about household conditions, such as the number of resident males and females. In Saudi Arabian culture, a son does not leave his parents' house until he is married, which means he will use the guestrooms to host friends. Some of the questions helped to identify levels of occupation between family members and male and female guests. Other questions in this section asked about the building, such as its age and the amount of floorspace allocated to various functions. In the case study house, for example, the villa was built in 2002 and had $350 \mathrm{~m} 2$ of ground floor space. The resident family included four children aged between 6 and 15 - two boys and two girls. The third section explored more detailed information about aspects of household behaviour that related to energy use. The questions focused on understanding how spaces were used. Emphasis was placed on temporal patterns of occupation, such as how rooms were used on a daily and occasional basis and typical levels of occupation within any one month. In the case study house, for example, there was just one guest room for both males and females, which was occupied around 90 to 100 times a year. The living hall was rarely used by the family, usually not more than once a month (because they have a family room for daily gathering), so it could be used by guests: this was possible as its aspect retained appropriate levels of privacy with regard to the rest of the house. The basement was used mostly during the weekend for friends gathering at night. Therefore, it was discovered from the survey that the guest room, dining room, living hall, and basement were not used on a daily basis. This contrasted with the kitchen, bedrooms, and family room, which were typically used daily.

The family did not use the heating, ventilation, and airconditioning (HVAC) system for heating during the winter, which is why the energy use in the winter was $60 \%$ lower than in the summer. Additionally, the family was normally absent for three to four weeks each August, which impacted energy use.

The fourth section focused on the information required to implement the time-use schedule. Participants were asked to complete schedules for weekdays and weekends. Data was collected for each 24-hour daily period and, from this, information was obtained about the occupation and use of rooms on an hourly basis (Table 2).
Table 2: Time-use schedule for this case study.
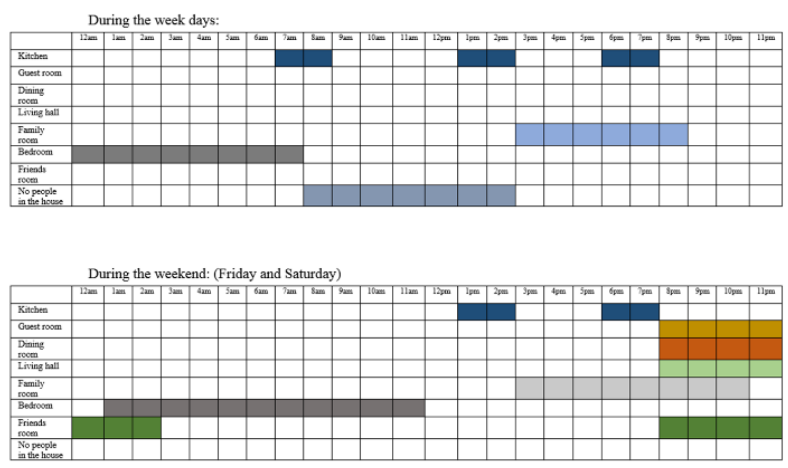

\section{Testing the model}

The third experimental stage was to run the simulation using information on the behaviour of occupants collected from the TUD survey. To obtain information to help formulate accurate survey questions, we tested the survey by running the simulation, analysing the results, finding weaknesses, and then improving the survey questions.

This process was repeated two more times until information was obtained that generated the most accurate simulations when compared with actual data.

The first version reduced the gap from $40 \%$ to $35 \%$. Based on this limited improvement, the questions were reexamined and it was discovered that they were confusing and easily misunderstood, especially those related to the time-use schedule. The survey questions were improved, tested for comprehension, and then data was collected again from the same occupants. Running the simulation using data derived from this new survey method produced outputs that reduced the gap from $40 \%$ to $25 \%$. Scrutinising the results further, it was discovered that insufficient consideration had given to seasonal variations in behaviour.

Questions were modified to explore winter behaviour in more detail. The survey results revealed that the HVAC system was turned off most of the time and was only turned on when the outside temperature dropped below $10^{\circ} \mathrm{C}$, which applied, typically, for less than one month in any year. However, in the OpenStudio software, the default schedule set the thermostat to $21^{\circ} \mathrm{C}$ for winter time, which meant that, when the outside temperature was over $21^{\circ} \mathrm{C}$, the heating would be on. This conflicted with the real energy-use data. In the third version of the survey, questions were asked about the temperature levels that were used to engage heating. The third simulation, which used this information, closed the gap from $40 \%$ to $15 \%$. This confirmed the importance of collecting information at this level of detail.

\section{Interviews}

The fourth experimental stage was to conduct interviews using an open-answer method. Before conducting the interviews, visual observations were made of the house to 
understand levels of privacy and to help identify subjects for investigation. We used Space syntax software to analyse the visual data and then applied it to the circulation diagram on the plan (Figure 4). The program analysed flows through the space.

The space syntax corresponded to the plan presented as a grid. In this case, we set the grid point spacing $(100,000)$, and the walls were defined as solid to block vision. The program defined the visibility volume from the number of points that touch other points in the space with no wall to block the connection (Figure 4). The highest connection in the plan, which means the highest visibility volume, was 2,850 points (the red colour on the plan [living hall]) and the lowest connectivity was 173 in the bathrooms and kitchen (dark blue on the plan). The main guest room showed the second-lowest level of connectivity on the plan. This shows that, in this case, the owners have one main guest room for both male and female occupants. A question arises as to whether this will be affected by the way in which the room is used: this was discussed with the householder. In addition, the female and family zones are joined together without walls and this is why this area displays the highest levels of visibility. This led to the discussion of three important points: circulation between the kitchen and the dining room through the female zone when guests are in the house; family and female guest circulation; and how people keep cool in open spaces.
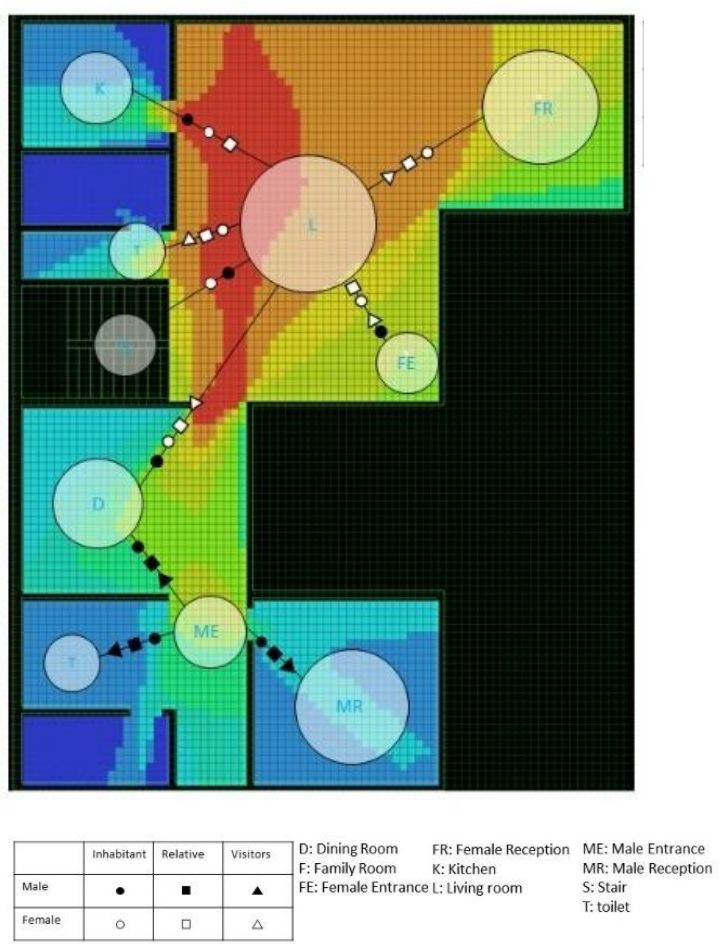

Figure 4: Space syntax analyses.

The interviews took around one hour for parents, and less for the children. The first part of the interviews explored the same information collected in the survey, but using open questions. The second part explored lifestyle and how the occupants used each room (activities) in detail; this embraced all waking hours and information obtained fed into time schedules. Other information collected was used to calibrate the questionnaire responses and identify any necessary design readjustments.

During the interviews, the occupants explained the ways in which the HVAC system was used. It was discovered that most people use the HVAC system for cooling in summer and for just a few days of heating in winter. This data was uploaded to the energy simulation software and used for the third (and most accurate) simulation.

\section{Summary of the experiments}

During the interviews, we found that the number of males and females living in a house, the size of the house, the year of its construction, the age of the householder, and the location were important factors that needed to be used in the simulations to improve accuracy. Figure 5 illustrates the monthly differential between the percentage of real and predicted energy use for each experiment.

The year the house was built was an important factor to consider as Saudi Arabians tend to use the guest zone less frequently nowadays. This is reflected in the design of more modern buildings.

The diagram shows the summary data for four outcomes. The $\mathrm{x}$-axis shows the four experimental outcomes by monthly bars, and the y-axis displays the percentage differences between predicted and actual energy uses: when the bar is lower than 0 , predicted energy use is lower than real energy use.

Experiment 1 (the default schedule) shows the largest gap between energy prediction and real energy use. In winter, the software prediction is higher than the real energy use; this is due to poor understanding of Saudi behaviour in the default schedule. The software incorrectly expected rooms to be heated, because the indoor temperature is lower than the comfort zone, and also failed to consider the usage of the guest rooms. On the other hand, in summer, the energy prediction is lower than the real energy use because of the extreme levels of cooling required in Saudi homes. This is much higher than the software predicted. Energy use is much higher in summer, but the percentage difference between predicted and actual energy use is lower than in winter (Table 3 ).

Experiment 2 compared real energy use with the model after applying the real data used for this case study manually in the model. The outcome shows no difference, which demonstrates the high accuracy of the input data from the ASHRAE standards used by EnergyPlus. 


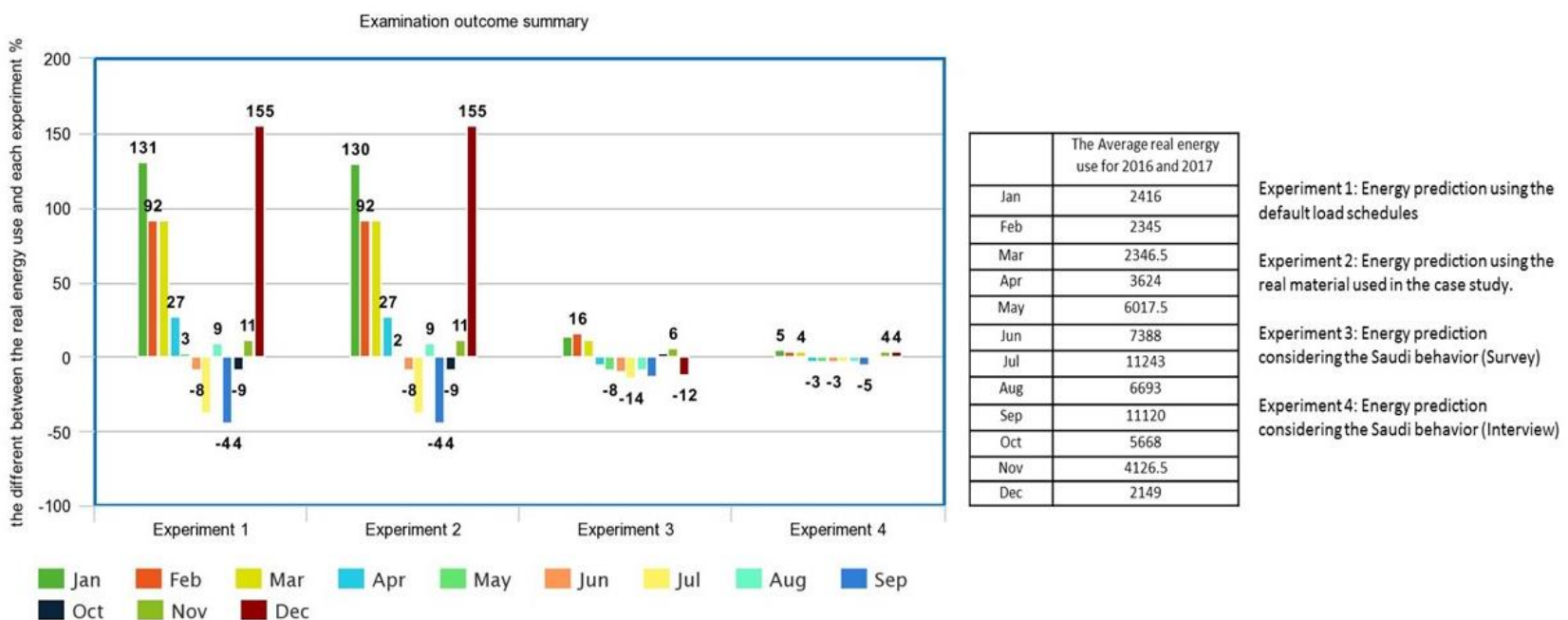

Figure 5: Examination outcome summary.

Experiment 3 incorporated data from the Saudi behaviour survey for the load schedules in the simulation. The percentage gap between predicted and real energy use dropped from $131 \%$ to $16 \%$ during the winter and from $44 \%$ to $14 \%$ in the summer. The 'annual' gap closed to 15\%. Experiment 4 also applied elements of Saudi behaviour in the load schedules. In this experiment, we interviewed the occupants and used their answers as input. The gap closed from 5\% to $4 \%$ in winter and from $5 \%$ to $3 \%$ in summer. The 'annual' gap closed to $5 \%$.

Table 3 gives a summary of the outcomes of all the experiments compared with the real energy use in 2016 and 2017. Column 5 shows the real energy use for 2017, column 6 shows the real energy use for 2016, and column 7 shows the average energy use for 2016 and 2017. The data in column 1 shows the outcomes of the first experiment in which the simulation was run using the

Table 3: Summary of the experiments. default load schedules. This highlights the gap between energy consumption and real energy use, without considering Saudi Arabian culture. Column 8 shows the percentage difference between the energy prediction and the real energy use, again without considering Saudi Arabian culture. Column 2 shows the results of the second experiment, which considered the real materials used in the construction of the building - rather than the defaults built into the energy software. The outcomes of the third experiment are shown in column 4, which considered people's behaviour using data taken from the first version of the survey. After completion of the survey, the questions went through several revisions to improve their effectiveness. Columns 10 and 11 show the outcomes of the third experiment when the data from the second and third versions of the survey were used. The last column shows the outcomes of the interviews with the occupants and the application of their behaviours to the load schedules.

\begin{tabular}{|c|c|c|c|c|c|c|c|c|c|c|c|}
\hline $\begin{array}{c}\text { Electricity } \\
\text { consumption }\end{array}$ & $\begin{array}{c}\text { Electricity } \\
\text { consumption } \\
\text { considering } \\
\text { the material }\end{array}$ & $\begin{array}{l}\text { Percentage } \\
\text { difference }\end{array}$ & $\begin{array}{c}\text { Electricity } \\
\text { consumption } \\
\text { considering the } \\
\text { behaviour }\end{array}$ & $\begin{array}{c}\text { Real } \\
\text { electricity } \\
\text { use } 2017\end{array}$ & $\begin{array}{c}\text { Real } \\
\text { electricity } \\
\text { use } 2016\end{array}$ & $\begin{array}{c}\text { AVERAGE } \\
2016 \text { and } \\
2017\end{array}$ & $\begin{array}{c}\text { Percentage difference } \\
\text { between the electricity } \\
\text { consumption and real } \\
\text { energy use }\end{array}$ & $\begin{array}{c}\text { Percentage } \\
\text { difference between } \\
\text { the electricity } \\
\text { consumption and } \\
\text { real energy use } \\
\text { considering the } \\
\text { behaviour }\end{array}$ & $\begin{array}{c}\text { Percentage } \\
\text { difference } \\
\# 2\end{array}$ & $\begin{array}{l}\text { Percentage } \\
\text { difference \#3 }\end{array}$ & Interview \\
\hline
\end{tabular}

\begin{tabular}{|c|c|c|c|c|c|c|c|c|c|c|c|c|}
\hline Jan & 5575 & 5525 & $1 \%$ & 2772 & 2041 & 2791 & 2416 & $131 \%$ & $15 \%$ & $30 \%$ & $14 \%$ & $5 \%$ \\
\hline Feb & 4509 & 4490 & $0 \%$ & 3709 & 2430 & 2260 & 2345 & $92 \%$ & $58 \%$ & $39 \%$ & $16 \%$ & $4 \%$ \\
\hline Mar & 4494 & 4482 & $0 \%$ & 3436 & 2261 & 2432 & 2346.5 & $92 \%$ & $46 \%$ & $33 \%$ & $12 \%$ & $4 \%$ \\
\hline Apr & 4592 & 4581 & $0 \%$ & 3296 & 3879 & 3369 & 3624 & $27 \%$ & $-9 \%$ & $-5 \%$ & $-5 \%$ & $-3 \%$ \\
\hline May & 6185 & 6120 & $1 \%$ & 4610 & 6672 & 5363 & 6017.5 & $3 \%$ & $-23 \%$ & $-8 \%$ & $-8 \%$ & $-3 \%$ \\
\hline Jun & 6792 & 6777 & $0 \%$ & 5224 & 7228 & 7548 & 7388 & $-8 \%$ & $-29 \%$ & $-10 \%$ & $-10 \%$ & $-3 \%$ \\
\hline Jul & 7016 & 7003 & $0 \%$ & 5414 & 11461 & 11025 & 11243 & $-38 \%$ & $-52 \%$ & $-14 \%$ & $-14 \%$ & $-3 \%$ \\
\hline Aug & 7284 & 7271 & $0 \%$ & 5184 & 9726 & 3660 & 6693 & $9 \%$ & $-23 \%$ & $-8 \%$ & $-8 \%$ & $-3 \%$ \\
\hline Sep & 6199 & 6178 & $0 \%$ & 4677 & 10805 & 11435 & 11120 & $-44 \%$ & $-58 \%$ & $-21 \%$ & $-12 \%$ & $-5 \%$ \\
\hline Oct & 5147 & 5134 & $0 \%$ & 3721 & 5714 & 5622 & 5668 & $-9 \%$ & $-34 \%$ & $3 \%$ & $3 \%$ & $2 \%$ \\
\hline Nov & 4570 & 4566 & $0 \%$ & 3500 & 4020 & 4233 & 4126.5 & $11 \%$ & $-15 \%$ & $6 \%$ & $6 \%$ & $4 \%$ \\
\hline Dec & 5478 & 5462 & $0 \%$ & 4687 & 2149 & 2149 & 2149 & $155 \%$ & $118 \%$ & $28 \%$ & $-12 \%$ & $4 \%$ \\
\hline
\end{tabular}




\section{Conclusions and Future Work}

The survey and the interviews revealed the complexities of how Saudi Arabian families use spaces, especially when guests are present. This behaviour is normal in Saudi Arabian culture. Based on expected standards of privacy, guests must have rooms that are separated visually from other rooms in the house. In addition, it was discovered that the HVAC system for heating is used in the winter for only a few days, and even then for only one or two hours when the ambient temperature is very low. This behaviour characteristic was not considered in the normal schedules for energy simulation models prior to this study.

In an Islamic country such as Saudi Arabia, there are a significant cultural behaviours that have a major impact on energy use. In this paper, our analysis has identified factors that, when considered appropriately, improve the accuracy of simulations considerably. Based on an initial case study in Riyadh, appropriate survey and data collection methods were designed that, when applied, reduced the inaccuracy gap from $40 \%$ to $15 \%$.

The findings of this research can serve as a foundation for larger-scale surveys that could be more representative of Saudi Arabian energy use in domestic buildings. We intend to look at cultural and behavioural factors in greater depth. To help refine and fine-tune the accuracy of simulation models further, we proposed that the TUD survey is extended to include approximately 400 participants in Riyadh. It is then intended that further focus should be given to improving the online survey method by using open-ended questions.

The TUD model in this paper can be applied throughout Saudi Arabia; however, the outcomes will not be as accurate outside Riyadh. Saudi Arabia is divided into five main regions: the regional capital of the middle region is Riyadh city (the capital of Saudi Arabia); the regional capital of east region is Damam city; the regional capital of the north region is Arar city; the regional capital of the west region is Makkah city; the regional capital of the south region is Asir city. All regions share the same religion and government regulations, but there are slight cultural differences, which are influenced by local climates and geography. In the future, researchers could use the same methods and apply them to the other regions. Together, these will provide greater insight into the use of space and home energy throughout Saudi Arabia and allow the simulation models to be improved further. This will also allow the results of simulations to be used with confidence in the design of future residential buildings. Islamic law applies in Saudi Arabia and $100 \%$ of the population are Muslim. Any country in which the population is $51 \%$ or more Muslim is considered Islamic, but the level of lifestyle influenced by Islamic culture may vary according to local circumstances.

\section{References}

Akbar, J.A. (1980). Support for court-yard houses: Riyad, Saudi Arabia. Thesis. Massachusetts Institute of Technology. http://dspace.mit.edu/handle/1721.1/15808.

Al-Hussayen, M. (1980). Building problems in Saudi Arabia: The need for building research, and the development of building research approaches, $\mathrm{PhD}$ Dissertation. The University of Michigan, Ann Arbor.

AlHemaidi, W. (1996). The dilemma of regulating privacy: Planning regulations, privacy and house form; the case study of low-density single-family dwellings in Saudi Arabia, PhD Thesis. University of London.

Aljammaz, Mohammed Hassan, Marc Schiler. (2016). "DAYLIGHTING TUBES IN RIYADH AND LOS ANGELES: Comparison of Cultural Factors in Potential Market Penetration". Full PapersPLEA2016.http://plea2016.uscarch.com/index.php/pl eapapers/fullpapers/paper/view/1468.

Al-Said F. (2003). The pattern of structural transformation of the Saudi contemporary neighbourhood: The case of Al-Malaz, Riyadh, Saudi Arabia. In 39th International Society of City and Regional Planners Congress.

Clarke, J.A. (2001). Energy Simulation in Building Design (2nd ed.). Oxford: Butterworth-Heinemann.

Data Archive Study Number 8128 - United Kingdom Time Use Survey, 2014-2015: University of Oxford (data collector form obtained from NatCen Social Research). '[ARCHIVED CONTENT] UK Government Web Archive - The National Archives.' n.d. Accessed July $14 \quad 2017$. http://webarchive.nationalarchives.gov.uk.

De Wilde, P. (2014). The gap between predicted and measured energy performance of buildings: A framework for investigation. Automation in Construction 41, 40-49. https://doi.org/10.1016/j.autcon.2014.02.009.

Korjenic, A. and Bednar, T. (2012). Validation and evaluation of total energy use in office buildings: A case study. Automation in Construction 23, 64-70. https://doi.org/10.1016/j.autcon.2012.01.001.

Lamedica, R., Capasso, A. and Prudenzi, A. (1994). A bottom-up approach to residential load modeling. IEEE Transactions on Power Systems 9(2), 957-64. https://doi.org/10.1109/59.317650.

Martinaitis, V., Zavadskas, E.K., Motuziene, V. and Vilutienè, T. (2015). Importance of occupancy information when simulating energy demand of energy efficient house: A case study. Energy and Buildings 101(August), 64-75. https://doi.org/10.1016/j.enbuild.2015.04.031.

Norford, L.K., Socolow, R.H., Hsieh, E.S. and Spadaro, G.V. (1994). Two-to-one discrepancy between measured and predicted performance of a 'low- 
energy' office building: Insights from a reconciliation based on the DOE-2 model. Energy \& Buildings 21(2), 121-31. https://doi.org/10.1016/03787788(94)90005-1.

Oberkampf, W.L. (2010). Verification and Validation in Scientific Computing [electronic resource]. Cambridge: Cambridge University Press.

Othman, Z., Aird, R. and Buys, L. (2015). Privacy, modesty, hospitality, and the design of Muslim homes: A literature review. Frontiers of Architectural Research 4(1), 12-23. https://doi.org/10.1016/j.foar.2014.12.001.

Paatero, J.V. and Lund, P.D. (2006). A model for generating household electricity load profiles. International Journal of Energy Research 30(5), 27390. https://doi.org/10.1002/er.1136.

Richardson, I., Murray, T. and David, I. (2008). A highresolution domestic building occupancy model for energy demand simulations. https://doi.org/10.1016/j.enbuild.2008.02.006.

Stokes, M., Rylatt, M. and Lomas, K. (2004). A simple model of domestic lighting demand. Energy \& Buildings 36(2), 103-16. https://doi.org/10.1016/j.enbuild.2003.10.007.

Sunikka-Blank, M. and Galvin, R. (2012). Introducing the prebound effect: The gap between performance and actual energy consumption. Building Research \& Information 40(3), 260-273. https://doi.org/10.1080/09613218.2012.690952.

Tanimoto, J., Hagishima, A. and Sagara, H. (2008a). Validation of probabilistic methodology for generating actual inhabitants' behavior schedules for accurate prediction of maximum energy requirements. Energy \& Buildings 40(3), 316-22. https://doi.org/10.1016/j.enbuild.2007.02.032.

Tanimoto, J., Hagishima, A. and Sagara, H. (2008b). A methodology for peak energy requirement considering actual variation of occupants' behavior schedules. Building and Environment 43(4), 610-19. https://doi.org/10.1016/j.buildenv.2006.06.034.

Widén, J., Molin, A. and Ellegård, K. (2012). Models of domestic occupancy, activities and energy use based on time-use data: Deterministic and stochastic approaches with application to various buildingrelated simulations. Journal of Building Performance Simulation 5(1), 27-44. https://doi.org/10.1080/19401493.2010.532569.

Wilke, U., Haldi, F., Scartezzini, J.-L. and Robinson, D. (2012). A bottom-up stochastic model to predict building occupants' time-dependent activities. Building and Environment. https://doi.org/10.1016/j.buildenv.2012.10.021.

Yoshino, H., Hong, T. and Nord, N. (2017). IEA EBC Annex 53: Total energy use in buildings - analysis and evaluation methods. Energy \& Buildings 152, 124136. https://doi.org/10.1016/j.enbuild.2017.07.038.
Yu, Z. (Jerry), Haghighat, F., Fung, B.C.M., Morofsky, E. and Yoshino, H. (2011). A methodology for identifying and improving occupant behavior in residential buildings. Energy 36(11), 6596-6608. https://doi.org/10.1016/j.energy.2011.09.002. 